\title{
The Study on Ergonomic Performances Based on Workstation Design Parameters using Virtual Manufacturing Tool
}

\author{
Mohd. Iqbal ${ }^{1}$, Iskandar Hasanuddin ${ }^{1 *}$, Azmi Bin Hassan ${ }^{2}$, Mohd Syafiq Mohd \\ Soufi $^{3}$, Friesca Erwan ${ }^{1}$
}

${ }^{1}$ Department of Mechanical and Industrial Engineering, Faculty of Engineering, Universitas Syiah Kuala, Jalan Syech Abdur Rauf, No 7, Darussalam, Banda Aceh, 23111, INDONESIA

${ }^{2}$ Electronic \& Automation Section,

Universiti Kuala Lumpur, Malaysian Spanish Institute, Kulim Hi-Tech Park, 09000, Kulim, Kedah, MALAYSIA

${ }^{3}$ Linier Semi-Conductor Sdn Bhd, Malaysia, Kuala Lumpur, MALAYSIA

*Corresponding author

DOI: https://doi.org/10.30880/ijie.2020.12.05.015

Received 21 May 2020; Accepted 28 May 2020; Available online 30 June 2020

\begin{abstract}
The paper discusses the dimensions of manual workstation in a semi-conductor industry and their effects to the ergonomic performances. The workstation provided quality control activity where the worker need to manually handle thousands of microchips and check their quality. Three dimensions were considered as workstation design parameters, namely as scope distance, scope height and chair height. Three measured were considered as ergonomics performances of the workstation, which were production cycle time, working posture and recommended weight limit. The performances are measured by using Method Time Measurement, Raid Upper Limb Assessment method and NIOSH recommended weight limit method respectively. The study was provided under a virtual manufacturing software. All of the workstation's components and the activities of the worker are modelled into Delmia V5 (Virtual Ergonomics Solution) software. Design of Experiment (DEO) was conducted by using Design Expert Statistical Software with Central Composite Design of Response Surface Methodology. Fifteen simulation experiments with different dimensions of design parameters were conducted as suggested by the DEO method. The results showed that production cycle time and working posture were affected by all of the design parameters. However, the weight limitation was only affected by scope height and chair height. The study continued to find the dimensions that gave the best ergonomic performance of the workstation.
\end{abstract}

Keywords: Workstation design, Ergonomics performances, Production Cycle Time, Working Posture and Weight Limitation.

\section{Introduction}

In engineering field, ergonomics studies become more important from time to time due to many injuries have been recorded at the workplace. In order to become high industrial and competitive country in the world, Industries should preserve its human resources and make the occupational safety and health as their main priority towards the workers. The occupational injuries caused by poor manual lifting techniques are a major occupational problem even in the highly industrialized countries. Thus, the field of Occupational Safety and Health (OSH) plays an important role in the engineering field to ensure the safety of workers at the workplace.

* Corresponding author email: iskandarhasanuddin@unsyiah.ac.id 
Day by day, there will be new technology to increase the productivity. Thus, new work procedures need to be taken by the workers to optimize the production in order to cope with the new technology. But there is almost no concern given to the consequences for the workers for the implementation of these new work procedures.

In ergonomics, poor body posture leads to a serious problem. Tasks which performed in proper working posture and frequent body movements would reduce the number of risks for musculoskeletal disorders [1]. A worker's discomfort, for example, due to body twisting while doing manual lifting puts unnecessary energy demands which by no means contribute to the declination in worker's productivity. In industry, workers should be provided with a manual guideline on how to prevent critical or awkward posture $[2,3]$ due to inappropriate workstation's designs and job tasks which lead to workplace injury [1]. Assessing body posture can be done through manual assessment such as using Nordic Musculoskeletal Symptom Survey or automatic systems such as a wireless and ambulatory posture monitoring system which can monitors the movement of the human body and detects the change of the body postures [4]. In addition, apart from body posture, workers need to have clear working procedures and working time, as well as suitable physical working environment with the job performed in the working area thus minimize psychology effect experienced by the workers while performing their tasks [5].

Applying ergonomics principles will enable workers to perform their tasks safely and efficiently. Therefore, it is essential to carefully design a workstation by implementing the principles recommended in ergonomics. It is important to study the effect of workstation design parameter on human performance, especially in manual working activity.

In industries, there are efforts to ensure that the workstation is safe for the workers. However, this ergonomics principle has always been neglected by most of the engineering companies, especially in manufacturing industries. The low level of implementation of ergonomics has close related to the occupational hazards [6]. In a Semiconductor industry, there are many complaints received from the workers that they experienced back pain while doing their work in a long period of time. This problem might affect their productivity to the company and also might affect their health. Many researchers have mentioned about the importance of implementing ergonomics principle in the workplace. However, there was a little study on the effect of different workstation design parameter on human performance in the manual working task, specifically in semiconductor industry. Therefore, this study seeks to find out the best design on the current workstation at a semiconductor industry.

The goal of this study is to improve the current workstation design of a semiconductor industry in order to improve the performance and health of the workers. The objectives of the study are be listed as follow:

1. To examine the layout design on the current workstation

2. To study the effect of workstation design parameter on ergonomics performances (cycle time, working posture and weight limitation)

3. To find the best design of the workstation based on optimum ergonomic performance.

\section{Methods}

Digital human model enables the study of product and process adaptation for people without any need of physical prototypes, therefore reduce the time and costs [7]. The use of a virtual reality environment in ergonomics enables the design evaluation conducted through virtual mock-ups, which is much less costly than traditional mock-ups. These virtual manufacturing simulations provides industrial applications either in the design or in the manufacturing processes such as to evaluate safety, operability or maintainability of a production line [6-8].

There are several types of CAD software that are available in the market. Some of these ergonomic software packages includes Delmia V5, UGS' Jack Software, ErgoIntelligence, Envision Ergo, ErgoEASER and SafeWork. This study used Delmia V5 (Virtual Ergonomics Solution) software to model the workstation's layout design and its activity then to study the related ergonomic performances.

\section{Result}

The inspection workstation in the assembly line of a semiconductor industry in Malaysia were studied in this research. Most of the assembly tasks were fully automatic but the considered inspection workstation, namely the 3rd opt workstation provided manual inspection tasks. A worker provided the following three stages of the task:

1. Lifting - the worker lifted the "magazine" from the rack to the workstation

2. Inspection - the worker inspected (in static position) every unit of the product from the magazine using a microscope.

Each magazine had thousands of units depending on the lot size

3. Lowering - the worker lowered the magazine once the inspection has been completed.

After 8 hours of continuous working, the workers experienced the pain at their back and neck, and muscle stress at their shoulders. Based on the interview and investigation of the workstation condition, a hypothesis was taken up that the pain and stress were caused by the poor design of the workstation. The workers need to bend their back and neck too low during the inspection and need to reach too far to the rack. However, lowering the rack and rising the table were not a simply solution since the affects were not linier, the space constrains need to be considered and several related performances need to be taken into account. 
The real picture of the workstation is shown in Fig. 1. The first figure (a) shows the real camera picture of a worker in his workstation. The second figure (b) shows two dimension approach which considered as workstation design parameters namely scope distance (A), scope height (B) and chair height (C). And, the third figure (c) shows the simulation model which developed by Delmia V5 software showing a worker and the workstation components.

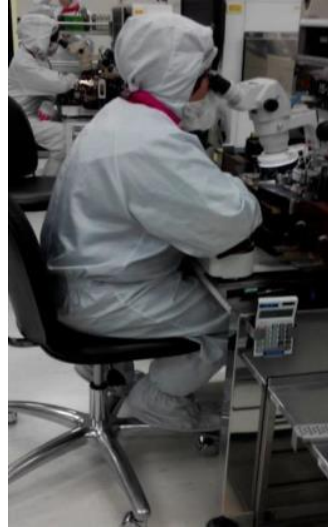

(a)

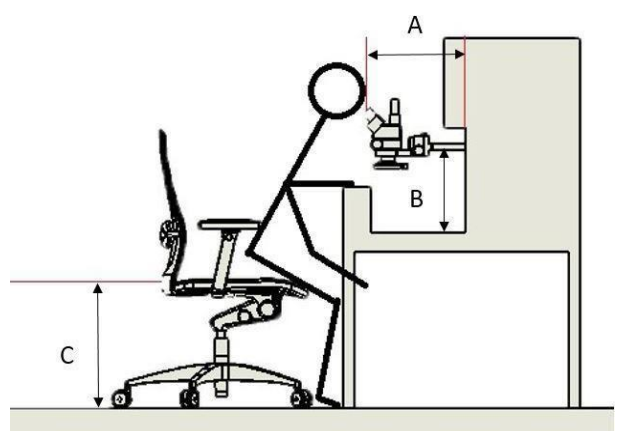

(b)

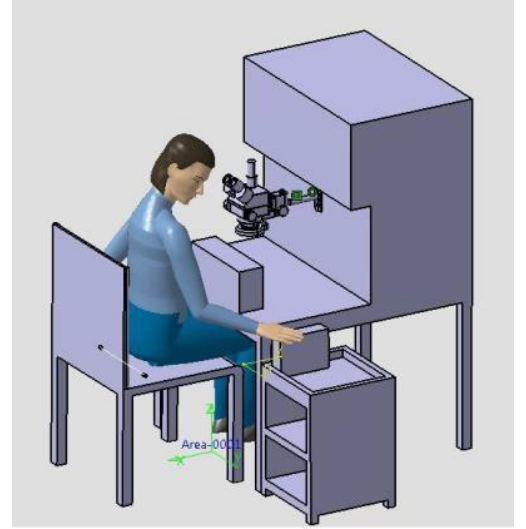

(c)

Fig. 1 - The workstation view in different visual approach: (a) Real camera picture; (b) 2D view; (c) Simulation model

Furthermore, Fig. 2 shows ergonomics performances of the workstation which consist of (a) production cycle time (Ttask), (b) working posture (Ptask) and (c) recommended weight limit (Wtask). The performances are measured using Delmia V5 software for Method Time Measurement (MTM), Raid Upper Limb Assessment (RULA) method and NIOSH recommended weight limit method respectively [9-11].

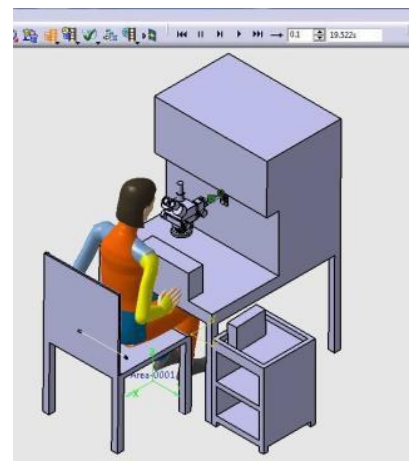

(a)

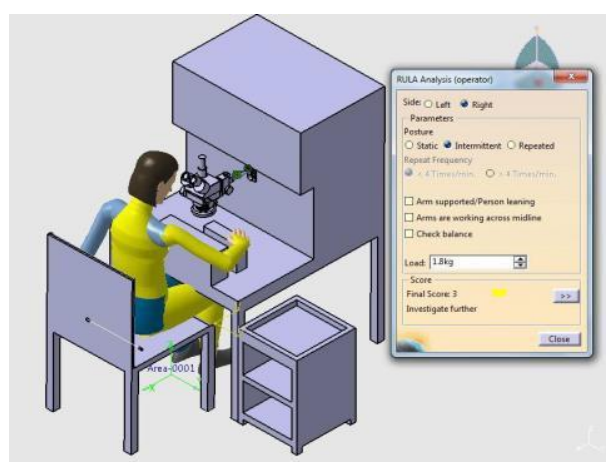

(b)

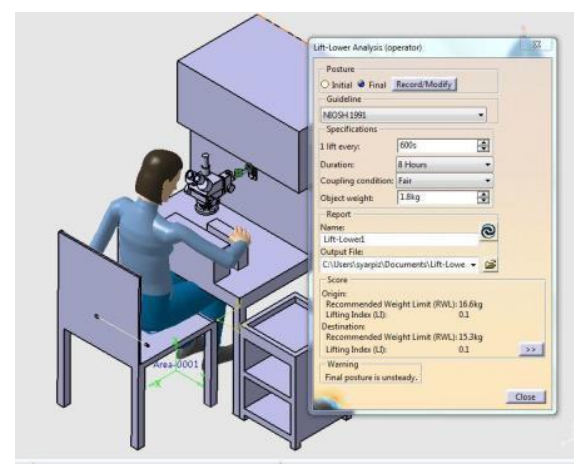

(c)

Fig. 2 - The workstation performances by Delmia V5 software: (a) Cycle time; (b) Working posture; (c) Weight limitation

Design of Experiment (DEO) was conducted using Design Expert Statistical Software with Central Composite Design of Response Surface Methodology [7], [12], [13], [14]. Based on the space constrain, the lower, middle and upper limit of the design parameters were set as shown in Table 1. Fifteen simulation experiments with different dimensions of design parameters were constructed by the DEO method as shown in Table 2.

Table 1 - The dimension of workstation design parameters

\begin{tabular}{ccccc}
\hline Parameters & \multicolumn{3}{c}{ Factor Level } & Delta \\
& $\mathbf{- 1}$ & $\mathbf{0}$ & 400 & 30 \\
A $(\mathrm{mm})$ & 340 & 370 & 305 & 20 \\
B $(\mathrm{mm})$ & 265 & 285 & 480 & 30 \\
C $(\mathrm{mm})$ & 420 & 450 & & \\
\hline
\end{tabular}


Table 2 - The result of the experiments

\begin{tabular}{ccccccc}
\hline Run & $\begin{array}{c}\text { Factor 1 } \\
\text { A: Scope } \\
\text { Distance }(\mathbf{m m})\end{array}$ & $\begin{array}{c}\text { Factor 2 } \\
\text { B: Scope Height } \\
(\mathbf{m m})\end{array}$ & $\begin{array}{c}\text { Factor 3 } \\
\text { C: Chair Height } \\
(\mathbf{m m})\end{array}$ & $\begin{array}{c}\text { Response 1 } \\
\text { Ttask } \\
(\mathbf{s})\end{array}$ & $\begin{array}{c}\text { Response 2 } \\
\text { Ptask }\end{array}$ & $\begin{array}{c}\text { Response 3 } \\
\text { Wtask } \\
(\mathbf{k g})\end{array}$ \\
\hline 1 & 400.0 & 305.0 & 420.0 & 19.362 & 5.124 & 16.086 \\
2 & 400.0 & 265.0 & 480.0 & 20.796 & 5.149 & 16.244 \\
3 & 370.0 & 285.0 & 450.0 & 19.522 & 4.868 & 16.067 \\
4 & 370.0 & 256.8 & 450.0 & 19.614 & 5.126 & 16.172 \\
5 & 370.0 & 285.0 & 450.0 & 19.522 & 4.868 & 16.067 \\
6 & 370.0 & 285.0 & 450.0 & 19.522 & 4.868 & 16.067 \\
7 & 340.0 & 265.0 & 420.0 & 19.66 & 5.267 & 16.028 \\
8 & 370.0 & 285.0 & 450.0 & 19.522 & 4.868 & 16.067 \\
9 & 370.0 & 313.2 & 450.0 & 19.75 & 5.186 & 16.112 \\
10 & 327.7 & 285.0 & 450.0 & 20.31 & 5.17 & 16.107 \\
11 & 370.0 & 285.0 & 492.3 & 20.387 & 5.325 & 16.143 \\
12 & 370.0 & 285.0 & 450.0 & 19.522 & 4.868 & 16.067 \\
13 & 370.0 & 285.0 & 407.7 & 20.108 & 5.331 & 16.132 \\
14 & 340.0 & 305.0 & 480.0 & 21.267 & 5.203 & 16.033 \\
15 & 412.3 & 285.0 & 450.0 & 20.048 & 4.729 & 16.281 \\
\hline
\end{tabular}

\section{Discussion}

Fifteen simulation experiments were conducted as suggested by the DOE. The performances were recorded based on the result that given by Delmia V5 software, as shown in Fig. 2. The results of the experiments were shown in Table 2. The results were then statistically analyzed by using Design Expert Software.

Analysis of Varian (ANOVA) showed that the model of the cycle time (Ttask) was significant with Fvalue $=2294.96$ and P-value probability $>\mathrm{F}$ is less than 0.0001 . Values of "Prob $>\mathrm{F}$ " less than 0.05 indicate model terms are significant. In this case A, B, C, AB, BC, A2, B2, C2 are the significant model terms which influence the value of Ttask. All of the design parameters gave significant effect to the cycle time as shown by the graphs in Fig. 3. It was clear from the ANOVA and Fig. 3 that all of the effects were not linier and interactions were occurred among all of the design parameters. Fig. 4 showed the effect of design parameters to the working posture (Ptask). Scope height and chair height gave significant effect to the working posture as shown by the graphs in Fig. 3 (a). Increasing the chair height from 420 to $450 \mathrm{~cm}$ will slightly decrease the PTask, but when the chair height increased from 450 to $480 \mathrm{~cm}$ the PTask increased exponentially. The interaction occurred between scope height and chair height, as shown in Fig. 4 (b). When the scope height increased at the lower level of the chair height, the Ptask increased. However, when the scope height increased at the higher level of the chair height, the Ptask did not change significantly. Fig. 5 shows the effect of design parameters to the weight limitation (Wtask). Scope distance and scope height gave significant effect to the working posture as shown by the graphs in Fig. 3 (a). Increasing the scope distance will decrease the WTask, and increasing the scope height will decrease the Wtask. No interaction among the design parameters were found.

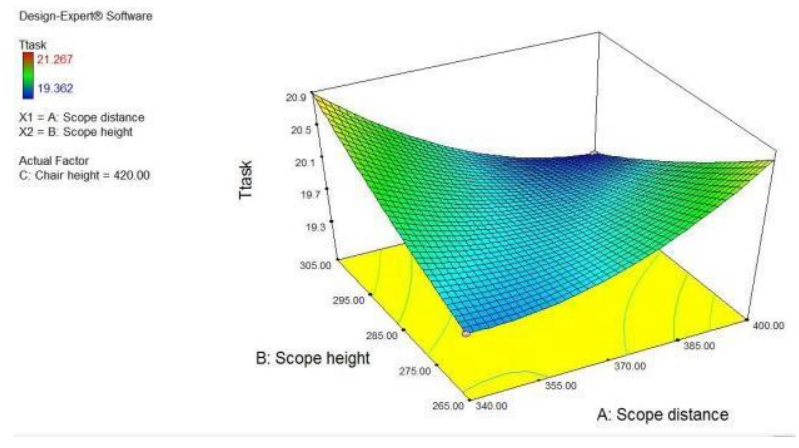

(a)

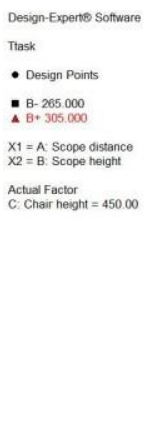

(b)

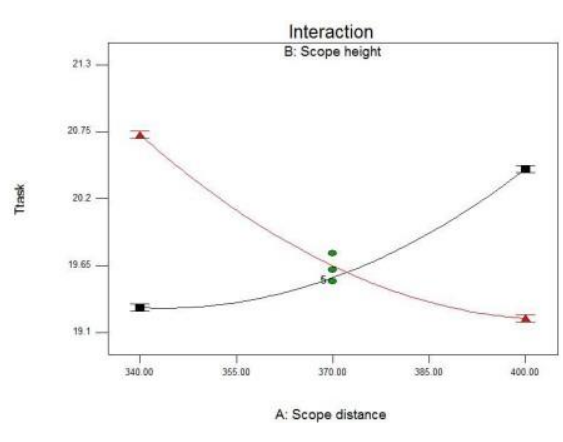

Fig. 3 - The graph for cycle time Vs design parameters: (a) Scope distance and scope height; (b) Scope distance 


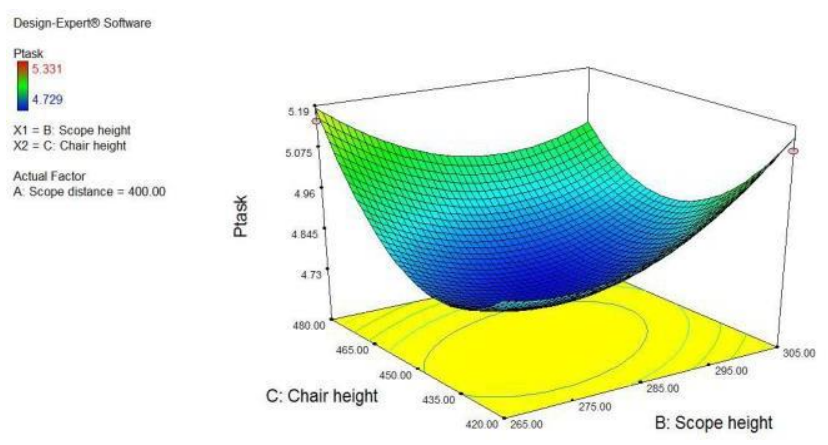

(a)

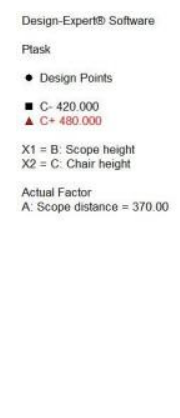

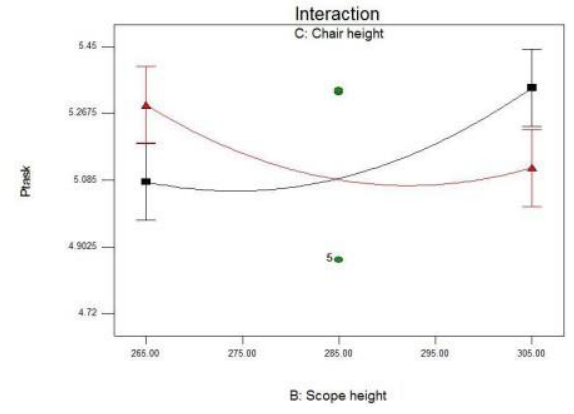

(b)

Fig. 4 - The graph for working posture Vs design parameters: (a) Scope height and chair height; (b) Scope height

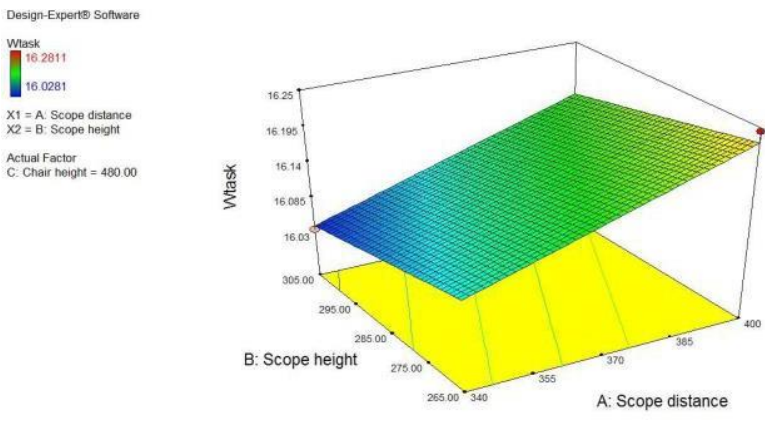

(a)
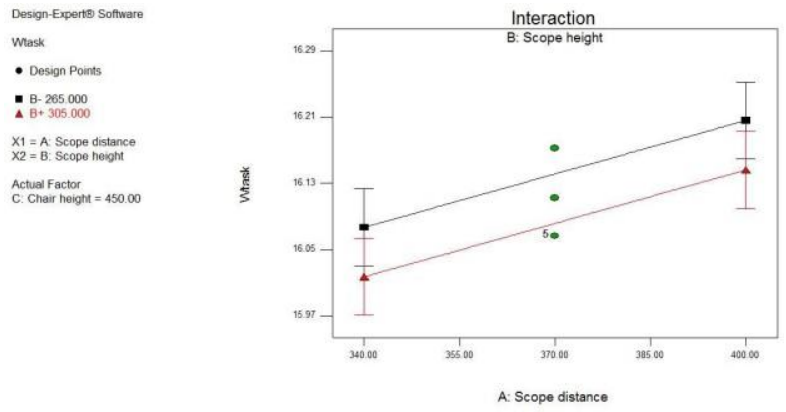

(b)

Fig. 5 - The graph for weight limitation Vs design parameters: (a) Scope distance and scope height; (b) Scope distance

The best configuration was selected by choosing the lowest cycle time, the lowest working posture value and the highest weight limitation. However, it was nearly impossible to gather all of the best conditions. Therefore, a subjective judgement was taken to select the closest ideal condition. As the result, experiment 15 has been considered as the best configuration (scope distance $=412.3 \mathrm{~cm}$, scope height $=285 \mathrm{~cm}$ and chair height $=450 \mathrm{~cm}$ ) that gave the best performance of the workstation (cycle time $=20.048$ seconds, working posture $=4.729$ and weight limitation $=16.281$ $\mathrm{kg})$.

\section{Conclusion}

The study on the effect of the design parameters (scope distance, scope height and chair height) to the ergonomic performances (cycle time, working posture and weight limitation) has been presented. This study reveals that the best configuration is selected by choosing the lowest cycle time, the lowest working posture value and the highest weight limitation. While, the best workstation design according to an optimum ergonomic performance is selected through a subjective judgment approach by looking the closest ideal condition amongst the experiment values obtained. In addition, all of the design parameters contributed significantly to the ergonomic performances. However, the level of contributions and interactions varied among the parameters. Further optimization study would be required in order to find optimum solution to measure ergonomics performances towards a workstation design.

\section{References}

[1] Halim, I., Radin Umar, R., Ahmad N., Jamli, M. R., Syed Mohamed, M. S., Moataz Albawab, T. M., Lim Abdullah, M. H., \& Padmanathan, V. (2018). Usability Study of Integrated RULA-KineticTM System for Wok Posture Assessment, International Journal of Integrated Engineering, 10(8), 175-184.

[2] Bridger, R. S. (2018). Introduction to Ergonomics. New York: CRC Press.

[3] Deros, B. M., Khamis, N. K., Ismail A. R., Jamaluddin, H., Adam, A. M., \& Rosli, S. (2011). An Ergonomics Study on Assembly Line Workstation Design, American Journal of Applied Sciences, 8(11), 1195-1201. 
[4] Low, E., Sam, T. H., Tee, K. S., Abdul Rahim, R., Saim, H., Wan Zakaria, W. N., Mohd Khialdin, S., Isa, H., \& Soon, C. F. (2020). Development of a Wireless and Ambulatory Posture Monitoring System, International Journal of Integrated Engineering, 12(2), 170-176.

[5] Erwan, F., Iqbal, M., \& Hasanuddin, I. (2018). The Analysis of Nursing's Work Systems in Relation to Burnout Syndrome (A Case Study: Nurses in RSUDZA, BLUD RSIA, and RSUD Meuraxa, Banda Aceh, Indonesia), IOP Conference Series: Materials Science and Engineering, 453, 012051.

[6] Ben-Gal, I., \& Bukchin, J. (2002). The Ergonomic Design of Workstations Using Virtual Manufacturing and Response Surface Methodology. IIE Transactions, 34(4), 375-391.

[7] Chaffin, D. B., (2008). Digital Human Modeling for Workspace Design. Reviews of Human Factors and Ergonomics, 4(1), 41-74.

[8] Zander. (2007). http://www.3ds.com/press-releases/single/vw-optimizes-ergonomic-integrity-with-dassaultsystemes-delmia-v5-human/.

[9] Mohamad, D., Deros, B. M., Ismail, A. R., Daruis, D./ D. L., \& Sukadarin. E. H. (2013). RULA Analysis of WorkRelated Disorder Among Packaging Industry Worker Using Digital Human Modeling (DHM). Advanced Engineering Forum, 10, 9-15.

[10] Morlock, F., Kreggenfeld, N., Louw, L., Kreimeier, D., \& Kuhlenkötter, B. (2017). Teaching Methods-Time Measurement (MTM) for Workplace Design in Learning Factories. Procedia Manufacturing, 9, 369-375.

[11] Cheung, Z., Feletto, M., Galante, J., \& Waters, T. (2007). Ergonomic Guidelines for Manual Material Handling, NIOSH Publication, 131.

[12] Myers, R. H., \& Montgomery, D. C. (2002). Response Surface Methodology, Process and Product Optimization Using Design Experiments ( $2^{\text {nd }}$ ed.). United States: John Wiley \& Sons Inc.

[13] Iqbal, M., Konneh, M., Ani, M. H., Abdallah, K. A., \& Binting, M. F. (2015). Cutting Temperature in High Speed Milling of Silicon Carbide Using Diamond Coated Tool. International Journal of Mechanical And Production Engineering, 3(4), 62-66.

[14] Iqbal, M., Konneh, M., Said, A. Y., \& Zaini, A. F. M. (2014). Surface Quality of Highspeed Milling of Silicon Carbide by Using Diamond Coated Tool. Applied Mechanics and Materials Journal, 446 - 447, 275-278. 